\title{
PENGARUH STRATEGI KNOW-WANT TO KNOW- LEARNED (KWL) TERHADAP PENGUASAAN KONSEP SISWA PADA MATERI EKOSISTEM
}

\author{
Nia Kurniasih*1, Milla Listiawati ${ }^{2}$ \\ Program Studi Pendidikan Bioogi, Program Sarjana S1, Universitas Islam Negeri Sunan \\ Gunung Djati Bandung; Jl. A.H. nasution No. 105 Cibiru- bandung 40614 /Tlp. 022-7802276 \\ Fax. 022-7802276/ www.ftkuinsgd.ac.id \\ $\underline{\text { millalistiawati@uinsgd.ac.id }}$
}

\begin{abstract}
Abstrak: Tujuan penelitian ini adalah untuk mengetahui pengaruh strategi KWL terhadap penguasaan konsep siswa pada materi ekosistem. Hipotesis penelitian ini adalah penggunaan strategi pembelajaran KWL pada materi ekosistem berpengaruh positif dan signifikan terhadap penguasaan konsep siswa. Metode yang digunakan adalah Quasi Eksperimental dengan desain nonequivalen control group design. Dalam penelitian ini yang menjadi populasi adalah siswa kelas VII SMP Negeri 1 Cileunyi. Sampel yang diambil dengan purposive sample, mengambil 2 kelas yaitu kelas VII-J sebagai kelas eksperimen dan VII-F sebagai kelas kontrol. Teknik pengumpulan data diperoleh dari tes (pilihan ganda) sebanyak 20 soal, dan nontes (angket dan lembar observasi). Pengolahan data dilakukan dengan analisis uji t. Penguasaan konsep siswa pada pembelajaran yang menggunakan strategi KWL 74,02 dengan kategori baik, sedangkan pada kelas yang tanpa menggunakan strategi KWL 64,51 dengan kategori cukup. Hasil uji t posttest pada taraf signifikan $0,05 \%$ didapat nilai thitung 11,73 $>t_{\text {tabel }}$ 1,67 sehingga Ho ditolak dan Ha diterima. Respon siswa yang menggunakan strategi KWL 80,40 dengan kategori sangat kuat, sedangkan kelas yang tanpa menggunakan strategi KWL 74,41 dengan kategori kuat. Keterlaksanaan pembelajaran guru yang menggunakan strategi KWL 96,66\% dan siswa 90,00\% dengan kategori sangat kuat sedangkan yang tanpa menggunakan strategi KWL guru 96,00\% dan siswa 80,00\% dengan kategori sangat kuat. Berdasarkan hasil penelitian dapat disimpulkan bahwa strategi Know-Want to know-Learned (KWL) berpengaruh positif dan signifikan terhadap penguasaan konsep siswa pada materi ekosistem.
\end{abstract}

Kata Kunci: Pengaruh, Strategi KWL, Penguasaan Konsep, Ekosistem

\begin{abstract}
:
The purpose of this study was to determine the effect of KWL strategy on students' mastery of the material concept of ecosystems. The hypothesis of this study is the use of learning strategies KWL on ecosystem material and significant positive effect on students' mastery of concepts.The method used was a quasi experimental design with control group design nonequivalen. In this study, the population was seventh grade students of SMP Negeri 1 Cileunyi. Samples were taken with a purposive sample, take two classes, namely the class as a class VII-A and VII-F experiment as a control class. Data collection techniques derived from the test (multiple choice) by 20 questions, and nontes (questionnaire and observation sheet). Data processing is done by t test analysis.Mastery of concepts students are learning to use $74.02 \mathrm{KWL}$ strategy with good category, while in the class without using the KWL strategy 64.51 with enough categories. The results of the posttest t test at significance level of $0.05 \%$ obtained tcount 11.73> 1.67 ttable so Ho is rejected and Ha accepted. The response of students who use the KWL strategy 80.40 with a very strong
\end{abstract}


category, whereas the class without using $74.41 \mathrm{KWL}$ strategy with strong category. Feasibility study of teachers who use the KWL strategy $96.66 \%$ and $90.00 \%$ of students with a very strong category, while the teacher without using KWL strategy $96.00 \%$ and $80.00 \%$ of students with a very strong category. Based on the results of this study concluded that the strategy of Know-Want to know-Learned (KWL) and a significant positive effect on students' mastery of the material concept of ecosystems.

Keywords: Effects, KWL Strategy, Concept Mastery, Ecosy

\section{PENDAHULUAN}

Tuntutan kurikulum dan hasil belajar siswa diharapkan dapat menambah ilmu pengetahuan, keterampilan dan pengalaman ketika mereka berada di lingkungannya, maka dalam pelaksanaan pembelajaran diperlukan suatu pembelajaran yang tepat dan sesuai dengan ruang lingkup sains di SMP/MTs, yaitu bekerja ilmiah dengan tujuan agar siswa dapat berlatih menguasai materi, pemahaman, dan penerapannya sebagai upaya memudahkan siswa berlatih untuk dapat mengkonstruksi konsep yang sedang dipelajari. Setiap siswa mempunyai kemampuan untuk melakukan persoalan ilmu pengetahuan yang diterima dalam kehidupan nyata.

Berdasarkan pengalaman ketika pelaksanaan Praktek Pengenalan Lapangan (PPL) proses belajar mengajar (PBMI) IPA khususnya mata pelajaran biologi, banyak siswa yang merasa kesulitan dalam mempelajari biologi. Kesulitan yang dialami siswa dalam mempelajari biologi disebabkan oleh beberapa faktor diantaranya adalah cara penyajian materi biologi yang kurang melibatkan aktivitas siswa, kurangnya media yang dibutuhkan siswa untuk membantu dalam memahami suatu konsep dalam pelajaran biologi, penggunaan pendekatan, model, atau metode pembelajaran yang digunakan oleh guru untuk menyampaikan materi pada siswa kurang menarik perhatian siswa sehingga siswa banyak yang merasa bosan bahkan mengantuk saat sedang belajar.

Berdasarkan studi pendahuluan, diperoleh keterangan dari guru biologi kelas VII SMP. Kebanyakan siswa pada umumnya mengalami kesulitan ketika memahami pelajaran biologi, salah satunya tentang ekosistem. Materi ekosistem ini sangat luas karena dalam ekosistem ini dipelajari tentang makhluk yang hidup (biotik) dan makhluk yang tidak hidup (abiotik) dan diantara komponen biotik dan abiotik itu akan terjadi saling interaksi, yang pada akhirnya akan membentuk rantai makanan dan menghasilkan energi. Karena materinya yang sangat luas dan banyak cakupannya, sehingga siswa merasa kesulitan untuk memahaminya, yang pada akhirnya tingkat penguasaaan konsep pun kurang memuaskan khususnya bagi peserta didik dan bagi guru pada umumnya.

Faktor lain yang mempengaruhi kurangnya penguasaan konsep siswa yaitu, para siswa sering sekali dihadapkan pada kesulitan menghapal dan memahami begitu banyak materi pelajaran, dihampir setiap pelajaran kegiatan yang sering dilakukan siswa ketika menerima pelajaran adalah mencatat dan mendengarkan. Umumnya siswa membuat catatan dalam bentuk tulisan yang linear hampir mencangkup seluruh isi materi pelajaran, sehingga catatan terlihat sangat monoton dan membosankan dan ketika dilakukan ulangan atau mengerjakan soal latihan, siswa akan mengerahkan energi. Oleh karena itu dengan strategi KWL diharapkan akan mampu membantu dalam penguasaan konsep siswa tentang materi ekosistem. Berdasarkan uraian di atas, dapat disimpulkan bahwa untuk melakukan penelitian ini diberi judul "Pengaruh Strategi Know-Want to knowLearned (KWL) Terhadap Penguasaan Konsep Siswa Pada Materi Ekosistem”. 


\section{METODE PENELITIAN}

Metode yang digunakan dalam penelitian ini adalah metode Quasi Eksperimen dengan desain penelitiannya nonequivalent control group design. Populasinya adalah seluruh siswa kelas VII VII SMP Negeri 1 Cileunyi sebanyak sebelas kelas VIIA sampai VII-K dengan jumlah 440 siswa.Sampel dalam penelitian ini adalah siswa kelas VII-F dan kelas VIIJ yang dipilih dengan teknik pengambilan purposive sample. Kelas VII-J sebagai kelas eksperimen sedangkan kelas VII-F sebagai kelas kontrol dengan jumlah siswa sama yaitu 41 orang. Teknik pengumpulan data diperoleh dari tes (pretest dan posttest) dan nontes (angket dan lembar observasi). Pengolahan data dilakukan dengan analisis uji statistik uji t.

\section{HASIL DAN PEMBAHASAN}

Keterlaksanaan proses pembelajaran aktivitas guru dengan menggunakan dan tanpa menggunakan strategi KWL dapat dilihat pada tabel 1.

Tabel 1. Aktivitas Guru pada Proses Pembelajaran

\begin{tabular}{|c|c|c|c|c|}
\hline \multirow{2}{*}{ Pertemuan } & \multicolumn{2}{|c|}{ Kelas Eksperimen } & \multicolumn{2}{c|}{ Kelas Kontrol } \\
\cline { 2 - 5 } & \multirow{2}{*}{ Rata-Rata } & Kategori & Rata-Rata & Kategori \\
\hline 1 & $90 \%$ & Sangat kuat & $90 \%$ & Sangat kuat \\
\hline 2 & $100 \%$ & Sangat kuat & $100 \%$ & Sangat kuat \\
\hline 3 & $100 \%$ & Sangat kuat & $100 \%$ & Sangat kuat \\
\hline Rata-rata & $96,66 \%$ & Sangat kuat & $96,66 \%$ & Sangat kuat \\
\hline
\end{tabular}

Selain pengamatan terhadap keterlaksanaan proses pembelajaran aktivitas guru, diamati pula aktivitas siswa baik dengan menggunakan Strategi KWL maupun tanpa menggunakan strategi KWL. Adapun data yang diperoleh dari hasil rata-rata lembar observasi dapat dilihat pada tabel.

Tabel 2. Aktivitas Guru pada Proses Pembelajaran

\begin{tabular}{|c|c|c|c|c|}
\hline \multirow{2}{*}{ Pertemuan } & \multicolumn{2}{|c|}{ Kelas Eksperimen } & \multicolumn{2}{c|}{ Kelas Kontrol } \\
\cline { 2 - 5 } & Rata-Rata & Kategori & Rata-Rata & Kategori \\
\hline 1 & $80 \%$ & Kuat & $70 \%$ & Kuat \\
\hline 2 & $90 \%$ & Sangat kuat & $80 \%$ & Sangat kuat \\
\hline 3 & $100 \%$ & Sangat kuat & $90 \%$ & Sangat kuat \\
\hline Rata-Rata & $90,00 \%$ & Sangat kuat & $80,00 \%$ & Kuat \\
\hline
\end{tabular}


Hasil analisis dan nilai posttest yang didapatkan dari siswa kelas eksperimen (menggunakan strategi KWL) dalam pembelajaran dengan materi ekosistem dapat dilihat pada tabel 3 .

Tabel 3. Penguasaan Konsep Siswa dengan Menggunakan Strategi KWL

\begin{tabular}{|c|c|c|}
\hline & Pretest & Posttest \\
\hline Rata-rata & 49,39 & 74,02 \\
\hline Kategori & Kurang & Baik \\
\hline
\end{tabular}

Adapun penguasaan konsep- siswa yang menggunakan strategi KWL perindikator dapat dilihat pada tảbel 4 .

Tabel 4 Rata-rata Indikator Penguasaan Konsep Siswa Menggunakan Strategi KWL

\begin{tabular}{|c|l|c|c|c|c|}
\hline \multirow{2}{*}{ No } & \multirow{2}{*}{ Penguasaan konsep } & \multirow{2}{*}{ Rata-rata } & Kualifikasi & \multirow{2}{*}{ Rata-rata } & \multirow{2}{*}{ Kualifikasi } \\
\cline { 3 - 6 } & & 52,68 & Kurang & 74,64 & Baik \\
\hline 1. & Mengingat (C1) & 49,48 & Kurang & 76,3 & Baik \\
\hline 2. & Memahami (C2) & 43,9 & Kurang & 65,17 & Baik \\
\hline 3. & Mengaplikasikan (C3) & 51,2 & Kurang & 78,05 & Baik \\
\hline 4. & Menganalisis (C4) & 49,31 & Kurang & 73,54 & Baik \\
\hline
\end{tabular}

Hasil analisis data nilai posttest yang didapatkan dari siswa kelas control dalam pembelajaran dengan materi ekosistem dapat dilihat pada tabel 5.

Tabel 5. Penguasaan Konsep Siswa Tanpa Menggunakan Strategi KWL

\begin{tabular}{|c|c|c|}
\hline & Pretest & Posttest \\
\hline Rata-rata & 46,95 & 64,51 \\
\hline Kategori & Kurang & Cukup \\
\hline
\end{tabular}

Adapun penguasaan konsep siswa yang menggunakan strategi KWL perndikator dapat dilihat pada tabel 6 .

Tabel 6 Rata-rata Indikator Penguasaan Konsep Siswa Tanpa Menggunakan Strategi KWL

\begin{tabular}{|c|l|c|c|c|c|}
\hline \multirow{2}{*}{ No } & \multirow{2}{*}{ Penguasaan konsep } & \multicolumn{2}{|c|}{ Pretest } & \multicolumn{2}{c|}{ Posttest } \\
\cline { 3 - 6 } & & \multirow{2}{*}{ Rata-rata } & Kualifikasi & Rata-rata & Kualifikasi \\
\hline 1. & Mengingat (C1) & 51,70 & Kurang & 70,26 & Baik \\
\hline 2. & Memahami (C2) & 49,47 & Kurang & 68,64 & Baik \\
\hline 3. & Mengaplikasikan (C3) & 34,75 & Gagal & 46,95 & Kurang \\
\hline 4. & Menganalisis (C4) & 48,80 & Kurang & 66,45 & Baik \\
\hline & Rata-rata & 46,18 & Kurang & 63,07 & Cukup \\
\hline
\end{tabular}


Setelah diketahui rata-rata hasil dari pretest pada kelas eksperimen dan kelas kontrol, dan selanjutnya dilakukan perhitungan uji normalitas, homogenitas dan uji hipotesis Postest untuk mengetahui seberapa besar pengaruh strategi KWL terhadap penguasaan konsep siswa pada materi ekosistem.
Untuk mengetahui normal atau tidaknya penyebaran nilai dari hasil posttest maka dilakukan uji normalitas. Hasil uji normalitas dapat dilihat pada tabel 7.

Tabel 7 Perhitungan Uji Normalitas Postest

\begin{tabular}{|l|c|c|}
\hline \multicolumn{1}{|c|}{ Harga yang dicari } & Kelas Eksperimen & Kelas Kontrol \\
\hline Rata-rata (x) & 73,45 & 64,18 \\
\hline Standar deviasi (sd) & 12,45 & 13,50 \\
\hline$X^{2}$ hitung. & 2,510 & 6,839 \\
\hline Derajat Kebebasan (dk) & 3 & 3 \\
\hline
\end{tabular}

\begin{tabular}{|l|c|c|}
\hline \multicolumn{1}{|c|}{ Harga yang dicari } & Kelas Eksperimen & Kelas Kontrol \\
\hline$X^{2}$ tabel. & 7,815 & 7,815 \\
\hline Taraf signifikan & $5 \%$ & $5 \%$ \\
\hline Keterangan & Normal & Normal \\
\hline
\end{tabular}

Setelah diketahui data berdistribusi normal, maka selanjutnya uji homogenitas. Hasil perhitungan uji hoogenitas dapat dilihat pada tabel 8 .

\section{Tabel 8. Perhitungan Uji Hipotesis Postest}

\begin{tabular}{|l|c|}
\hline \multicolumn{1}{|c|}{ Harga yang dicari } & Hasil \\
\hline Varians besar $(\mathrm{Vb})$ & 12,45 \\
\hline Varians kesil $(\mathrm{Vk})$ & 13,50 \\
\hline$F_{\text {hitung }}$ & 1,18 \\
\hline$F_{\text {tabel. }}$ & 1,69 \\
\hline
\end{tabular}

Setelah kedua data berdistribusi normal dan variansnya homogen, maka dilanjutkan dengan uji t. hasil perhitungan uji t dapat dilihat pada tabel 9. 
Tabel 9. Hasil Perhitungan Uji Hipotesis Postest

\begin{tabular}{|c|c|c|c|c|c|}
\hline \multirow{2}{*}{ Kelas } & \multicolumn{2}{|c|}{ Nilai Rata-rata } & \multirow{2}{*}{ t } & \multirow{2}{*}{ tabel } & \multirow{2}{*}{ Keterangan } \\
\cline { 2 - 3 } & Postes & Sd & thitung & & Terdapat \\
\hline Eksperimen & 74,02 & 12,45 & & & \\
\hline & & & 11,73 & 1,67 & Pengaruh \\
\hline
\end{tabular}

Berdasarkan tabel 3.8 diatas dapat diketahui bahwa nilai thitung $=11,73>$ $\mathrm{t}_{\text {tabel }}=1,64$, maka Ho di tolak dan $\mathrm{Ha}$ diterima yang berarti terdapat perbedaan yang positif dan signifikan pada pembelajaran yang menggunakan strategi KWL, hal ini berarti strategi KWL berpengaruh positif dan signifikan terhadap penguasaan konsep siswa pada materi ekosistem.

Data untuk mengetahui respon siswa terhadap pembelajaran yang telah dilakukan, maka digunakan skala likert yang tujuannya untuk mengidentifikasi kecenderungan atau sikap siswa. Respon siswa kelas eksperimen terhadap pembelajaran dengan menggunakan strategi KWL diperoleh rata-rata keseluruhan 80,40 dengan kategori Sangat kuat, sedangkan respon siswa terhadap pembelajaran tanpa menggunakan strategi KWL diperoleh rata-rata keseluruhan 74,41 termasuk dengan kategori Kuat. Rata-rata respon antara kelas eksperimen dan kontrol dapat dilihat pada gambar 1 .

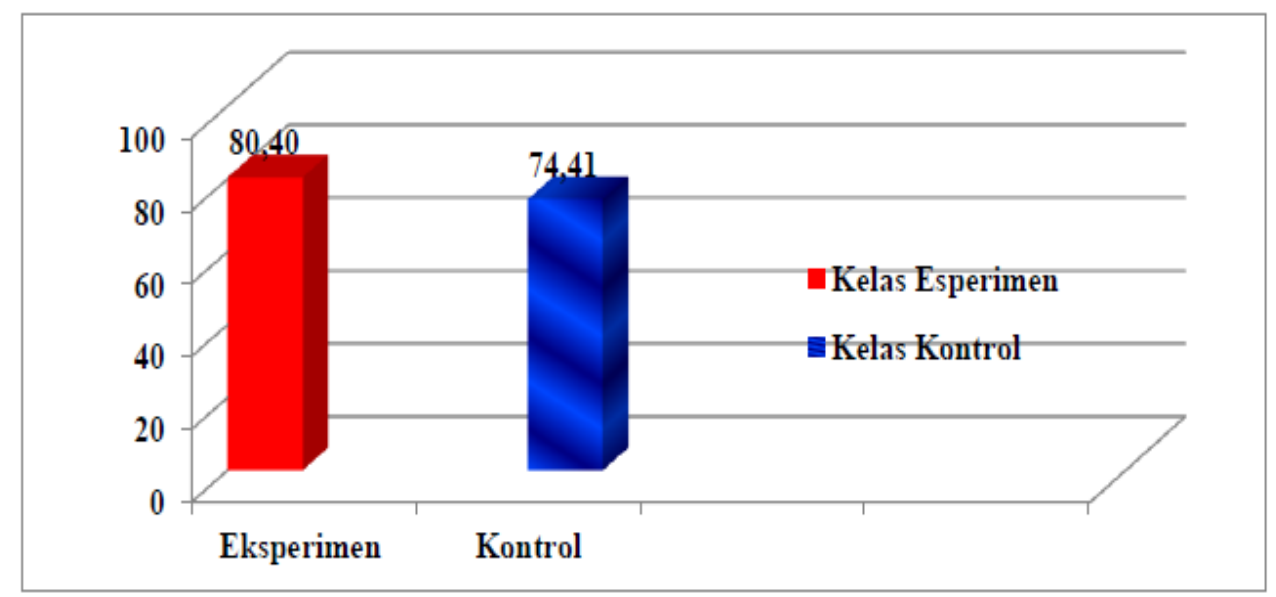

\section{Gambar 1. Respon Siswa Kelas Eksperimen dan Kelas Kontrol}

\section{PEMBAHASAN}

Hasil penelitian bertujuan untuk mengetahui ada atau tidaknya pengaruh strategi KWL terhadap penguasaan konsep siswa pada materi ekosistem. hasil penelitian ini dilihat dari pretest dan posttest. Pelaksanaan pretest dan posttest dalam penelitian ini menggunakan soal sebanyak 20 soal berupa pilihan ganda. Kemudian hasil pretest dan posttest baik pada kelas eksperimen maupun kelas kontrol diolah dengan perhitungan analisis uji t.

Menurut Purwanto (2013: 107) faktor yang memengaruhi proses belajar pada setiap orang dapat diikhtisarkan sebagai berikut: faktor luar dan faktor dalam. Faktor luar diantaranya lingkungan dan instrumental. Lingkungan dipengaruhi oleh alam dan sosial, sedangkan 
instrumental dipengaruhi oleh kurikulum (bahan ajar), guru (pengajar), sarana dan fasilitas, dan administrasi(manajemen). Faktor dalam yaitu fisiologi dan psikologi. Psikologi dipengaruhi oleh kondisi fisik dan panca indera, sedangkan psikologi dipengaruhi oleh bakat, minat, kecerdasan, motivasi dan kemampuan kognitif.

Ditegaskan oleh Isjoni (2011: 26) bahwa dalam Cooperative learning, para siswa dapat membuat kemajuan kearah pengembangan sikap, nilai dan tingkah laku yang memungkinkan mereka dapat berpartisipasi dalam komunitas mereka. Sehingga terciptanya tujuan utama Cooperative learning yaitu untuk memperoleh pengetahuan dengan temannya.

Penggunaan strategi KWL dalam proses belajar mengajar dipengaruhi oleh peran guru dalam pencapaian hasil belajar. Hal tersebut tidak lepas dari peran guru sebagai fasilitator dan pembimbing selama proses belajar mengajar berlangsung. Hal ini juga sependapat dengan sanjaya (2009: 14) mengatakan bahwa tugas guru adalah membimbing siswa agar siswa berkembang sesuai dengan tugas-tugas perkembangannya, melatih keterampilan baik keterampilan intelektual maupun keterampilan motorik sehingga siswa dapat dan berani hidup di masyarakat yang cepat berubah dan penuh persaingan, memotivasi siswa agar mereka dapat memecahkan berbagai persoalan hidup didalam masyrakat yang penuh tantangan dan rintangan, membentuk siswa yang memiliki kemampuan inovatif dan kreatif dan lain sebagainya.

Menurut Syah (2000: 85) dalam peningkatan kecakapan kognitif yang perlu dikembangkan segera khususnya oleh guru yaitu strategi belajar memahami isi materi pelajaran dan strategi meyakini arti penting materi pelajaran aplikasinya serta menyerap pesan-pesan moral yang terkandung dalam materi pelajaran tersebut.

Data lain yang digunakan sebagai data penunjang dalam penelitian ini yaitu respon siswa terhadap penerapan strategi KWL mencangkup indikator, yaitu: minat siswa terhadap pelajaran biologi, minat siswa terhadap materi ekosistem, kesiapan siswa dalam belajar dan minat siswa terhadap strategi belajar. Hasil yang diperoleh mengenai respon siswa terhadap strategi KWL pada materi ekosistem pada kelas eksperimen memperoleh rata-rata sebesar 80,40 termasuk kateogori sangat kuat, sedangkan hasil perhitungan angket respon siswa terhadap strategi KWL memiliki respon positif untuk digunakan dikelas. Hal ini dapat dilihat dari rata-rata yang diperoleh termasuk kategori cukup kuat.

Selain menggunakan angket sebagai data penunjang, juga digunakan lembar observasi guru dan siswa dengan tujuan untuk mengukur tingkah laku individu atau proses terjadinya suatu kegiatan yang dapat diamati, baik dalam situasi yang sebenarnya maupun dalam situasi buatan. Berdasarkan analisis yang telah dilakukan dapat diketahui bahwa aktivitas guru dan siswa selama proses pembelajaran dengan menggunakan strategi KWL pada pertemuan ke-1 sampai pertemuan ke-3 mengalami peningkatan.hal ini dapat dilihat dari perolehan nilai rata-rata aktivitas guru sebesar 96,66 \% dengan kategori sangat kuat dan rata-rata aktivitas siswa sebesar 90,00\% dengan kategori sangat kuat.

Selain kendala-kendala yang dihadapi, tidak sedikit pula kemudahan yang didapatkan ketika proses pembelajaran. Guru hanya bertugas sebagai fasilitator yang mengarahkan siswa agar lebih aktif berinteraksi dengan teman-temannya.

Siswa lebih medah memahami materi, karena suasana belajar lebih kondusif sehingga meningkatkan gairah dan semangat belajar siswa dalam belajar. Proses pembelajaran tidak akan berjalan dengan baik apabila tidak ada kerjasama antara guru dan siswa, serta antara siswa dengan siswa lainnya.

\section{DAFTAR PUSTAKA}

Anderson L. W \& Krathwohl D.R. (2010). Kerangka Landasan untuk Pembelajaran, Pengajaran dan 
Asesmen (Revisi Taksonomi Pendidikan

Bloom). Yogyakarta Pustaka Pelajar.

Arikunto, S. 2008. Dasar-dasar Evaluasi Pendidikan. Jakarta: Bumi Aksara.

Arikunto, Suharsimi. (2013). Dasar-Dasar Evaluasi Pendidikan. Jakarta: PT Bumi Aksara.

Campbell, Reece dan Mitchell. 2004. Biologi Edisi Kelimal Jilid 3. Jakarta: Erlangga.

Carr, E. \& Ogle, D. (1987). K-W-L Plus: A Strategy for Comprehension and Summarization. Journal of Reading, 30 (7), 626-631. Diperoleh 2 Mei 2014, dari http: //eric.ed.gov/ERICWebPortal.

Dahar, R. W. 2011. Teori-teori Belajar dan Pembelajaran. Jakarta: PT Gelora. Aksara Pratama.

Djamarah, Syaiful Bahri. (2011). Strategi Belajar Mengajar. Jakarta : PT Rineka Cipta.

Faudy, Amir. dkk, (2012). Pengaruh Strategi Know Want to Learn (KWL) Dan Minat Membaca Terhadap Kemampuan Membaca Intensif Siswa SMP Negeri Di Temanggung" (Jurnal Penelitian Bahasa Sastra Indonesia dan Pengajaran). Diperoleh 2 Juni 2014, http://portalgaruda.org/article.

Gulo. W. (2008). Strategi Belajar Mengajar. Jakarta: PT Grasindo.

Hamdani. 2011. Strategi Belajar Mengajar. Bandung: Pustaka Setia.

Hamruni, 2011. Strategi pembelajaran. Yogyakarta: insan Madani.

Hendrik, (2010), Uji mann-whitey (UTes) tersedia (onlein) : http://lady mh 89.files wordpress com. / / ladymh 89 files com/2011/08, Uji Man whitey I.pdf (diunduh pd juli 2014).

Huffman, L.E. (1998). Spotlighting Specifies by Combining Focus Questions with K-W-L. Journal of Adolescent \& Adult Litaracy, 41(6), 470-472. Diperoleh 24 Juni 2014, dari http: // eric.ed.gov/ERICWebPortal.
Irwan, D. 2007, Prinsip-prinsip Ekologi

Ekosistem, Lingkungan dan Pelestariannya. PT. Bumi Aksara: Jakarta

Isjono, 2011. Cooperative Learning Efektifitas Pembelajaran Kelompok ALFABETA: Bandung.

Jihad, Asep. Haris, Abdul. 2009, Evaluasi Pembelajaran. Yogyakarta: Multi Pressindo.

Kariadinata, Rahayu. 2011. Statistik Pendidikan Suatu Pengantar. Bandung: FTK UIN SGD Bandung.

Maulana. (2009). Memahami Hakikat, Variabel, dan Instrumen Penelitian Pendidikan dengan Benar. Bandung: Learn2live ' $\mathrm{n}$ Live2learn.

Purwanto, Ngalim. 2013. Psikologi Pendidikan. Bandung: PT Remaja Rosdakarya.

Rahim, Farida, 2009. Pengajaran Membaca Di Sekolah Dasar, Jakarta: bumi aksara.

Riduwan, M. (2009). Dasar-dasar statistika. Bandung: Alfabeta.

Rustaman, Nuryani (2003).Strategi Belajar Mengajar Biologi. Bandung: IKIP. Jakarta.

Sagala, Syaiful. (2012). Konsep dan Makna Pembelajaran. Bandung: Alfabeta.

Sanjaya, Wina 2009. Strategi Pembelajaran Berorientasi Standar Proses pendidikan. Jakarta: kencana.

Sapari, Heri Busyaeri. (2013). Efektivitas Pendekatan Metakognisi Strategi KWL (Know-Want-Learned) Dalam Upaya Meningkatkan Kemandirian Belajar" (Tesis). (Skripsi Universitas Pendidikan Indonesia). Tersedia [online]: http://repository.upi.edu/pdf. [diunduh 2 juni 2014].

Slameto. 2010. Belajar dan Faktor-faktor Yang Mempengaruhi Belajar" Jakarta: PT Rineka Cipta.

Soemarwoto. Otto. 2004. Ekologi Lingkungan Hidup Dan Pembangunan. Djambatan: Jakarta.

Subana. (2000). Statistik Pendidikan. Bandung: CV Pustaka Setia. 
Sudijono, Anas. 2011. Pengantar Evaluasi Pendidikan. Jakarta: PT Raja Grafindo Persada.

Sudirman, dkk. 1991. Ilmu Pendidikan. Bandung: PT Remaja Rosdakarya.

Sudjana. 2005. Metode Statistik. Bandung: Tarsito

Sugiyono. 2010. Statisitka Untuk Penelitian. Bandung : Alfabeta.

Sugiyono. 2013. Metode Penelitian Pendidikan (Pendekatan Kuantitatif, Kualitatif, dan $R \& D)$. Bandung : Alfabeta.

Sumardi. (2010). Uji Nonparametik. (Jurnal Universitas Mercubunana). Tersedia (online): http://statprobmdl14ujinonparame trik.co.id. [diakses pada 13 Juni 2014]

Sumarjito. 2004. Strategi Tembus Perguruan Tinggi. Yogyakarta: Andi Offest.

Suprijono, Agus. (2009) Cooperative Learning Teori Aplikasi Paikem. Yogyakarta.

Syah, Muhibin. 2000. Pisikologi Pendidikan. Jakarta: Raja Grafindo Persada.

Tim Penyusun Kamus. (2008). Kamus Besar Bahasa Indonesia. Tersedia (online):

http://id.shvoong.com/socialsciences/education/2258711penguasaan-konsep/ [diakses pada 13 Maret 2014]

Trianto. (2003). Model-model Pembelajaran inovatif Berorientasi Konstruktivisik. Jakarta: Prestasi Pustaka.

Undang-Undang Republik Indonesia No. 20 Tahun 2003. 2004. Sisdiknas (Sistem Pendidikan Nasional). Surabaya: Karina.

Uno, Hamzah.B \& Nurdin Mohamad. 2012. Belajar dengan Pendekatan PAILKEM. Jakarta: Bumi Aksara.

Wena, Made, (2009). Strategi Pembelajaran Inovatif Kontemporer. Jakarta: Bumi aksara. 